\title{
On sublinks and their connections within the graphs of the mechanically bound molecules
}

\author{
Myroslav O. Vysotsky ${ }^{\mathrm{a}, \mathrm{b} *}$ \\ ${ }^{a}$ Abteilung für Lehramtskandidaten der Chemie, Fachbereich Chemie, Pharmazie und \\ Geowissenschaften, Johannes - Gutenberg Universität, Duesbergweg 10-14, 55128 Mainz, \\ Germany \\ ${ }^{b}$ Brüder-Grimm Str. 59, 55218 Ingelheim, Germany \\ E-mail: m.o.vysotsky@googlemail.com
}

\begin{abstract}
The concept of sublinks has been further developed and has been used in the new form for the analysis of the graphs of complex mechanically bound molecules. This analysis is additionally supported by the Brunnian numbers $\mathrm{M}, \mu$ for topologically non-trivial and their complements $\mathrm{L}$ and $\lambda$ for topologically trivial systems (like [n]-rotaxanes). The detailed topological analysis has been thus performed for more than thirty topologically different structures. The different orders of (sub)links, single and multiple mechanical bonds ought to be discerned to analyze connections within the larger structures. The new nomenclature recommendations developed suggest to indicate the number of the mechanical bonds, their (highest) multiplicities together with the number of covalent units and the number of interlocked rings or rings and dumbbells.
\end{abstract}

Key words: Borromean rings, catenanes, mechanical bonds, molecular necklaces, nomenclature, rotaxanes, sublinks

\section{Table of Contents}

1. Introduction

2. Sublinks as constitutional parts of the graphs of the mechanically bound molecules

3. Basic differences between "composition" and mechanical connection of (sub)links

4. On the numbers of ordinary mechanical bonds

5. Multiple mechanical bonds

6. Hierarchy of (sub)links

7. Sublinks as building blocks in construction of more complex structures

8. Proposal for nomenclature of the mechanically built systems

Conclusions 
Acknowledgements

References and notes

\section{Introduction}

There was enormous progress made within the last decade in the chemistry of mechanically bound systems, ${ }^{1}$ which comprises catenanes, ${ }^{2}$ rotaxanes, ${ }^{3}$ their multiple versions, ${ }^{4}$ knots ${ }^{5}$ and Borromean rings. ${ }^{6}$ The interest towards such structures is due to their very promising and feasible applications predominantly in nano-technologies. ${ }^{7}$ The topological structures of these compounds (e.g. multiple catenanes, knots, Borromean rings, etc.) have appealed idealistically many chemists also just to synthesize them and thus to test the already known templation reactions ${ }^{8}$ or perhaps to discover new and more effective ones. The complexity of such systems increases each year, which leads some times even to the contradictions with the existing nomenclature recommendations. Such trends reflect, on the other hand, the strong need to perfect further our understanding of the composition of such systems that should then lead to the appearance of new nomenclature rules. In here, I would like to demonstrate and analyze some examples without and with existing contradictions just to support the idea mentioned above. For example, it is suggested to indicate the number of the covalently built units within the square brackets of the names of structures like catenanes or rotaxanes. Thus, the number "2" in [2]rotaxane 1 and [2]-catenane 2 (Figure 1) means, that either one macrocycle and one dumbbelllike axle (in 1) or two macrocycles (in 2), all in all two covalent units, are connected mechanically with each other. Consequently, [3]- 3 and [4]-catenanes 4 consist of three or four macrocycles, respectively, that is totally understandable and correct. However, there are some recent examples of multiple versions of catenanes or rotaxanes, ${ }^{9}$ which have been synthesized on the bases of self-assembled capsules of the tetraureas of calix[4]arenes (Figure 2). ${ }^{10}$ Bis-[2]catenane 5 possesses two covalently built units but has two pairs of the entangled macrocycles, which are intrinsically implicated in calix[4]arene skeletons. Strictly speaking, this name means only the double set of [2]-catenanes and no other type of connections, but it reflects rather well the structure of 5. Bis-[3]-catenanes 6 are similar with the exception that two pairs of [3]catenanes are now present in two covalently built units. Additionally, four macrocycles of the last [3]-catenane assembly, are fused with each other. In the same time [8]-catenanes 7 have eight mechanically entangled macrocycles, though the number of covalently built units remains the same. The authors, obviously, have taken the number of the entangled rings as the property, that is reflected in the names of these compounds. I have a strong feeling the artificially made structures with mechanical connections can be of even higher complexity. That is why the nomenclature rules for the names of these compounds should be also once again verified, improved and should easily reflect the main properties of such connections in these compounds. 

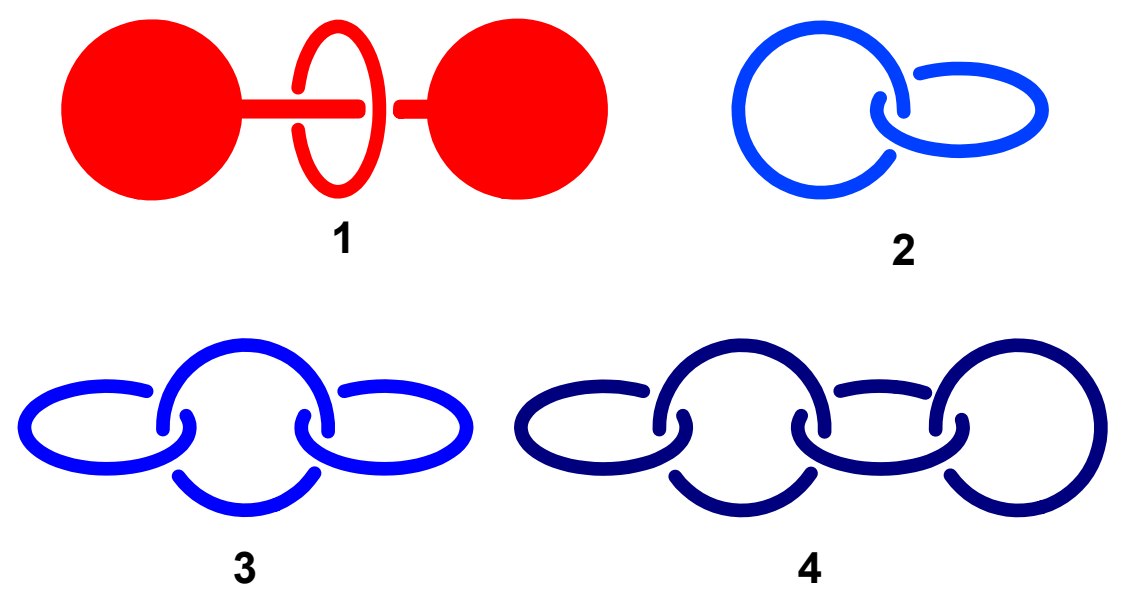

Figure 1. Examples of simple "topologically interesting" and mechanically bound structures 1-4.

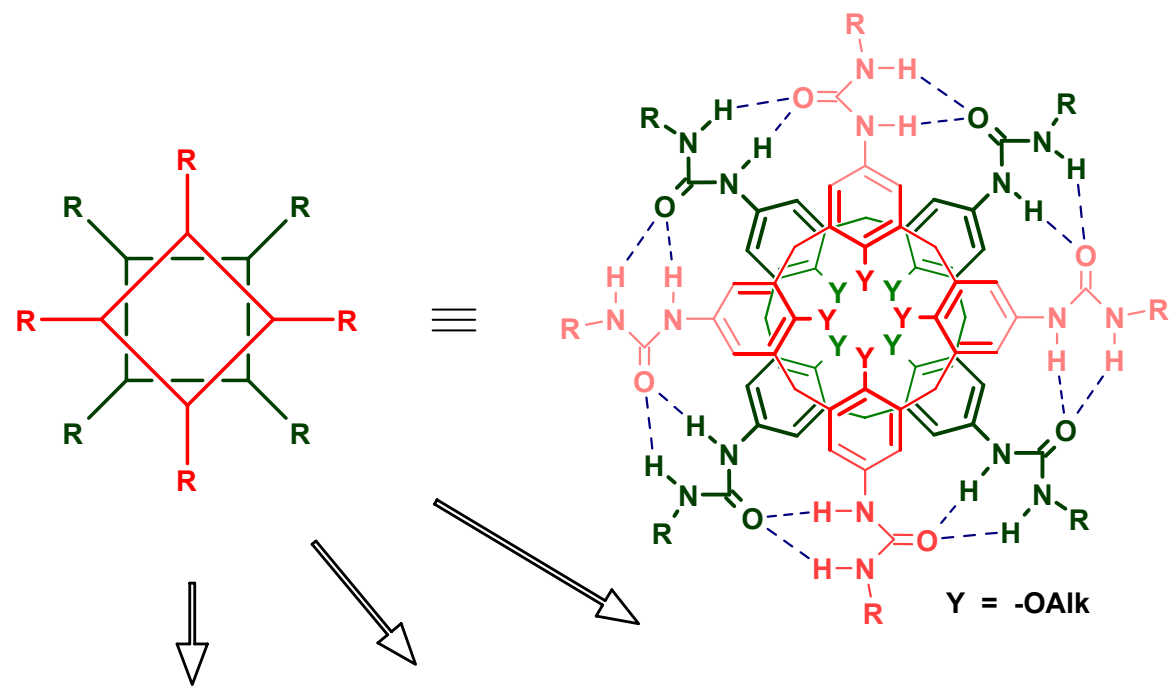

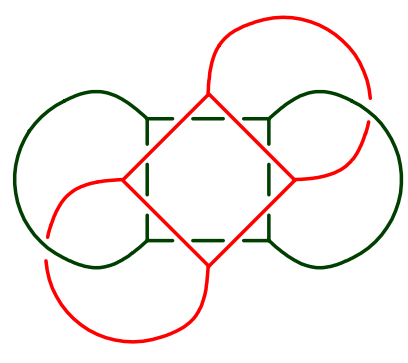

5

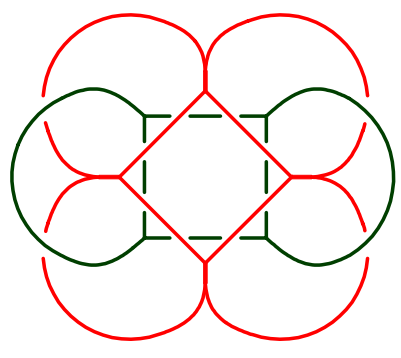

6

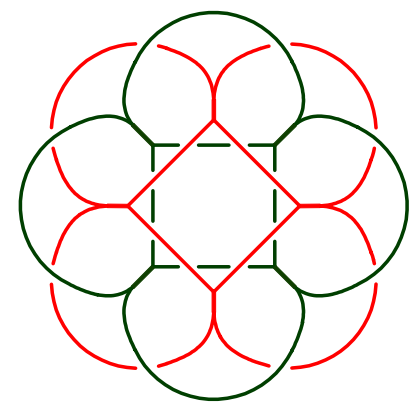

7

Figure 2. Multiple catenanes 5 - 7 obtained on the bases of the self-assembled molecular capsules of tetra urea calix[4]arenes. The last ones are schematically represented up right.

In this article I develop further the concept of sublinks, which has been once coined for the 
analysis of complex Borromean rings. ${ }^{11}$ In contrast to the works on sublinks performed in algebraic topology, ${ }^{12}$ chemists need instead of too abstract, simple but in the same time sufficiently reliable tools, which are important for chemical structures in terms of quality of the constitutional units, their quantities and types and quantities of their connections. I am sure, due to the further development of this concept here one can: (1) analyse rationally such complex systems; (2) analyse correctly the mechanical connectivites between constitutional parts (e.g. sublinks), and thus (3) develop further the synthetic approaches towards such compounds. Some proposals are made towards the nomenclature of the mechanically bound molecules.

\section{Sublinks as constitutional parts of the graphs of the mechanically bound molecules}

The existing retro-synthetic approach proved to be irreplaceable when the right strategies in syntheses of complex organic compounds ought to be choosen. ${ }^{13}$ This method appeared as methodology in the time when chemists struggled to synthesize more and more complex structures known mainly from the natural sources. Obviously, we all use such an approach even subconsciously each time when we plan to make even very easy chemical compounds. Syntheses of [2]-rotaxanes 1 are good examples of retro-synthetic methodology in the field of mechanically built structures. There are the following general methods known: (1) threading-followed-bystoppering, ${ }^{14}$ (2) "clipping," ${ }^{15}$ and (3) slippage. ${ }^{16}$ A very elegant application of retro-synthetic methodology has been recently used in design of both magnificent and very efficient synthesis of Borromean rings, ${ }^{6 \mathrm{a}}$ that needs only one pot procedure to make the desired compounds in up to $90 \%$ (!) yield starting from only the linear precursors and using transition metal cations as templates.

The concept of sublinks is somewhat similar to the retro-synthetic methodology. For the analysis of complex links, I propose to represent their graphs as the sum of graphs of their constitutional parts without (some) mechanical bonds. Such constitutional parts have been already called sublinks, when similar but not exactly the same analysis of complex Borromean rings had been undertaken (Figure 3). ${ }^{11}$ To the best of my knowledge, this approach has not yet been extended to the other classes of either "mechanically bonded" or in a very general sense "topologically interesting" compounds. However, I personally see the proposal once mentioned ${ }^{11}$ as only the first step in such analysis, since the meaning of sublink, for us chemists, is deeper than it is presented there.

The analysis published ${ }^{11}$ uses also two different characteristics $M$ and $\mu$, which are called cutting or Brunnian numbers (Zerschneidungszahlen). ${ }^{17}$ "If a topologically non-trivial link is considered (e.g. Borromean ring 8), such cuts should be applied to the rings. This leads to the separation of the ring cut from the intact $\operatorname{ring}(\mathrm{s}) . " 11$ The number $\mathrm{M}$ is equal to such cuts needed to disconnect a given Borromean link in the longest way possible to finish up with the topologically trivial situation (Figure $3 \mathrm{a}$ ). And $\mu$ corresponds to the number of cuts made on the 
shortest way to do it. If $M>1$, there are at least two counterparts present, which had been called sublinks. The known example to demonstrate it, is the Borromean ring $\mathbf{8}^{11}$ (Figure 3). If only one cut is applied to any of the rings "1" (i, Figure 3a), the system becomes topologically trivial having five rings 9 ( "1" + "2" + 2 x "3" + "4") and one linear unit. Thus, $\mu=1$. The longest way to disconnect $\mathbf{8}$, is to make cut in one of the rings 3 (iii, Figure 3a), that gives 10, then cut ring 4 (iv), that gives 11 and finally cut any of the rings remained. Thus, $M=3$. There is also the intermediate situation possible with $M=2$, when the first cut is made within the ring 2 (ii), that leads to the system 12 and then cutting any of the rings of 12 leads to the topologically trivial situation. The topological properties of all structures presented in this article, are comprised in Table 1 (see also later).

The cutting numbers are obviously very helpful in such analysis and they are used throughout in this manuscript also. However, the cutting itself leads to some non cyclic structures at the very end, that is, in my opinion, not helpful. I would like to stress that unlike the method published, ${ }^{11}$ I propose to represent a given link as the sum of sublinks. It means, the mechanical bonds between sublinks should (partly) disappear, which can be actually made in three operations: 1) cutting(s) one of the units (this operation is the same as in finding $M$ and $\mu$ ); 2) disconnection of units thus obtained and 3) repairing the unit(s) (e.g. rings) previously cut. In this way, there are four possibilities for $\mathbf{8}$, which have to be considered (Figure 3b): 1) six rings 9; or 2) one Borromean ring 10 and two 9; or 3) one Borromean ring 11 and three 9 or, finally, 4) one Borromean ring 12 and one 9. In this way, any covalent unit present ought to be considered as a sublink, also "simple" rings 9.

Now, such approach can be applied to the analysis of other mechanically bound systems like catenanes, that has not been done yet. To illustrate it, the full analysis of [5]-MN ( $\mathrm{MN}=$ molecular necklace) ${ }^{18} \mathbf{1 3}$ is presented (Figure 4), where four external (or "exo") macrocycles are connected to the central (or "endo") macrocycle. In this system $\mathrm{M}=4$, if cuts are made only within the "exo" macrocycles, however $\mu=1$, if only one cut is made within the "endo" macrocycle. Since sublink is a part of a link, there are four combinations possible: 1) five macrocycles 9 ; 2) one [2]-catenane 2 and three macrocycles 9 ; 3) one [3]-catenane 3 and two macrocycles 9; 4) one simpler molecular necklace [4]-MN 14 and one macrocycle 9. All these constitutional parts can be regarded as sublinks of [5]-MN. That means, sublinks can be not only differentiated by (a) topology (trivial or not trivial), ${ }^{11}$ but also (b) by the number of covalently built units within each sublink (one or more) and thus by (c) by the number of mechanical bonds themselves present in such sublinks (see later). 
a)
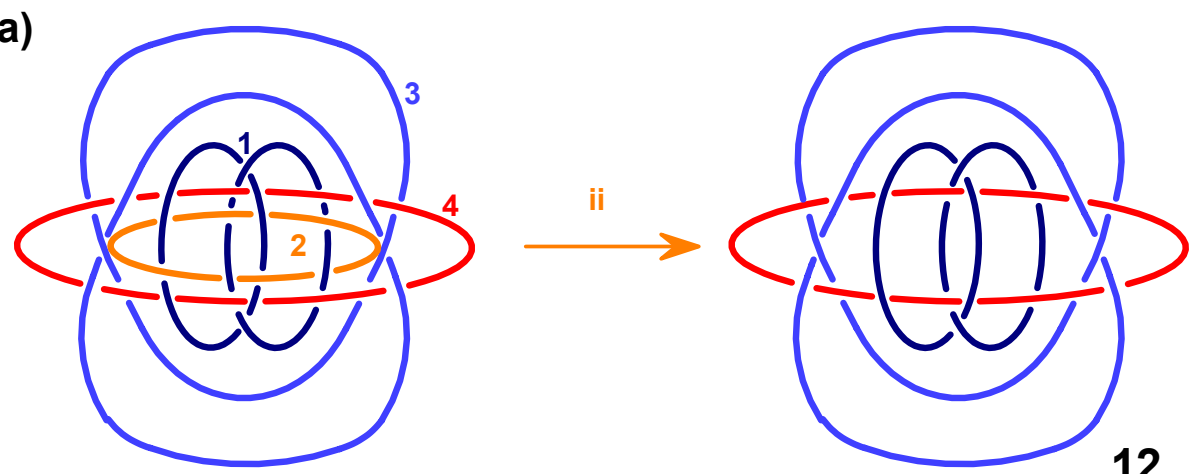

8
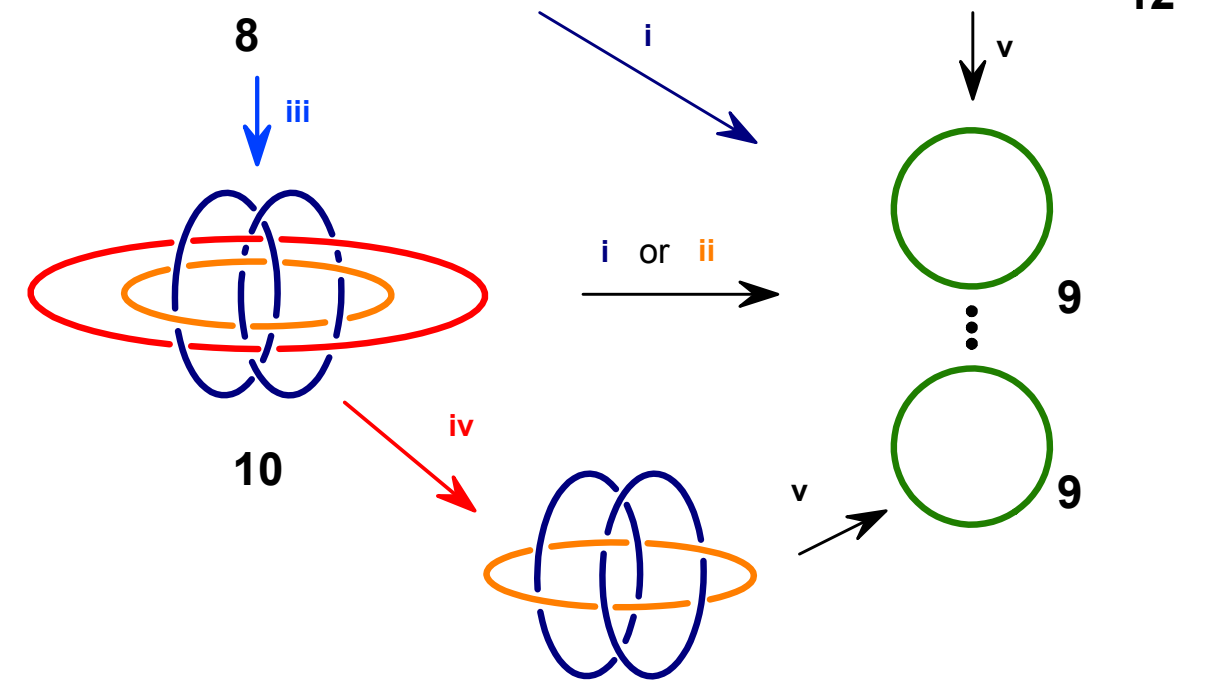

12

11

b)

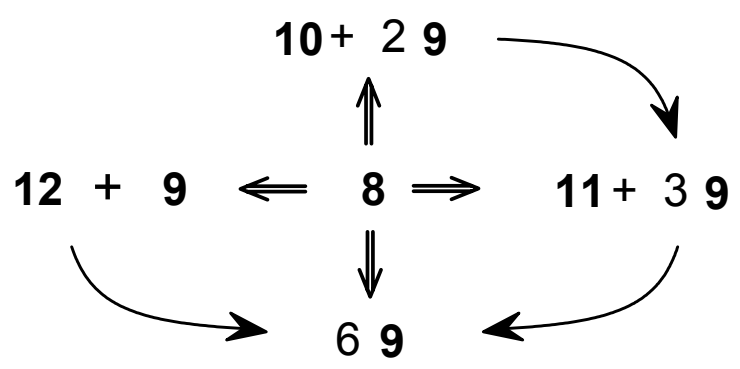

Figure 3. Structural analysis of complex Borromean links on the example of 8: a) made in the previous work (adapted with permission from the ref. 11); b) proposed in here. The cutting operations: i) cutting any of the rings 1 (dark blue); ii) cutting the ring 2 (orange); iii) cutting any of the rings 3 (light blue); iv) cutting the ring 4 (red); v) cutting any of the remaining rings.

I would like to stress once again that the method proposed here is only similar to the wellknown retro-synthetic analysis. The difference is obvious. Synthons are plausible intermediates (or precursors), which are supposed to give the desired compounds. In the case presented here, sublinks are constitutional parts, but not necessary synthons, which would lead to the formation 
of the desired structure. At least one of synthons must be by the conditions, an acyclic structure. The only exception of this rule seems to be the slippage methodology in synthesis of rotaxanes ${ }^{16}$ (and thus all similar syntheses ${ }^{19}$ ). However, the analysis presented can be of a great help to choose various synthetic ways towards topologically complex structures such as [5]-MN (Figure 4, Table 1).

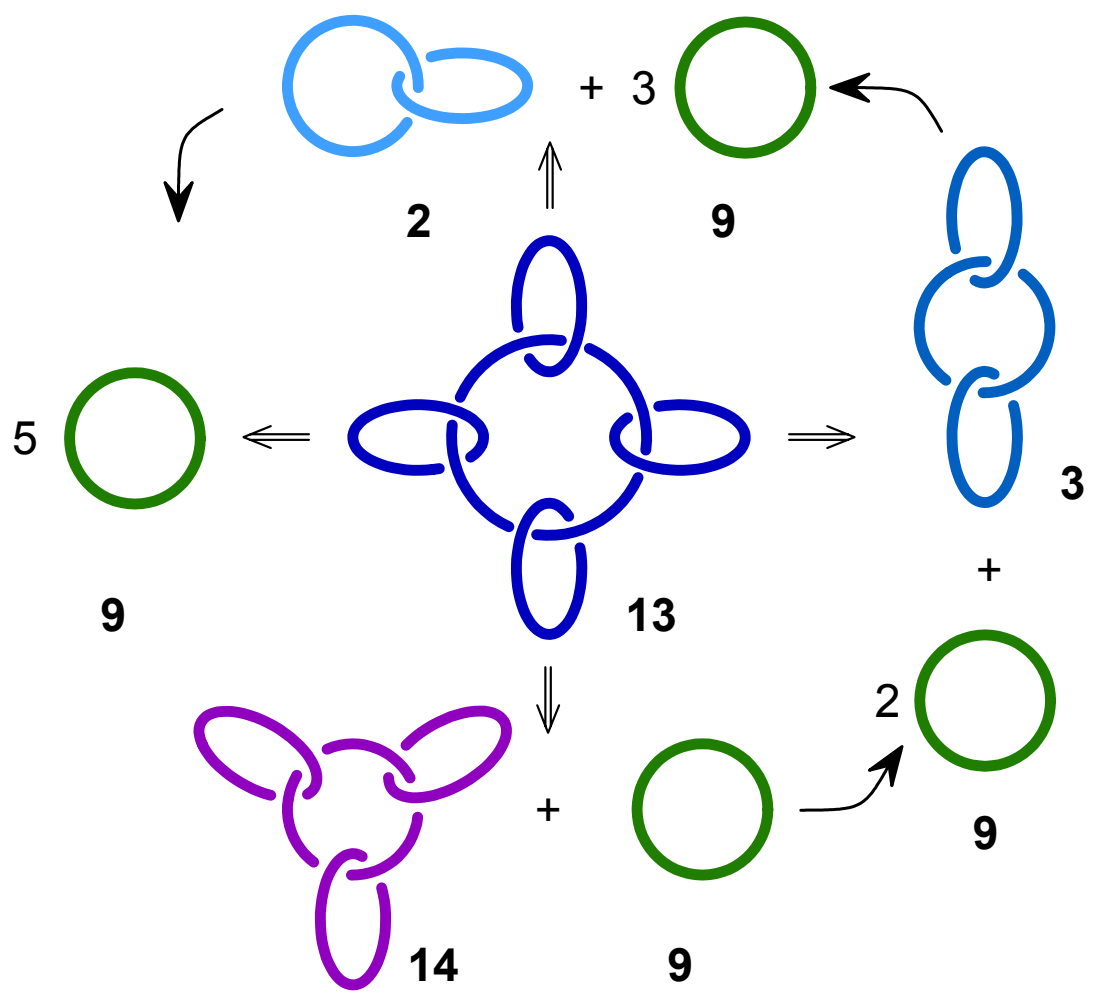

Figure 4. Analysis of molecular necklace 13. The topological properties of all structures are indicated in Table 1. 
Table 1. Topological properties of the structures met in this article: topology (trivial "t.", nottrivial "n.t."), number of covalent units (N.C.U.), Brunnian numbers (M, $\mu, \mathrm{L}, \lambda)$, number of molecular bonds (MB), the highest multiplicity of molecular bonds met in a given structure (MMB)

\begin{tabular}{|c|c|c|c|c|c|c|c|c|c|}
\hline Link & Graph & $\mathrm{T}$ & N.C.U. & $\mathrm{M}$ & $\mu$ & $\mathrm{L}$ & $\lambda$ & $\mathrm{MB}$ & MMB \\
\hline 1 & & t. & 2 & 0 & 0 & 1 & 1 & 1 & 1 \\
\hline 2 & & n.t. & 2 & 1 & 1 & - & - & 1 & 1 \\
\hline 3 & & n.t. & 3 & 2 & 1 & - & - & 2 & 1 \\
\hline 4 & & n.t. & 4 & 3 & 2 & - & - & 2 & 1 \\
\hline \multirow{2}{*}{5} & & n.t & 2 & 2 & 2 & - & - & 2 & 1 \\
\hline & & n.t. & 2 & 4 & 2 & - & - & 4 & 1 \\
\hline 7 & & n.t. & 2 & 7 & 3 & - & - & 8 & 1 \\
\hline 8 & & n.t. & 6 & 3 & 1 & - & - & 4 & 5 \\
\hline 9 & & t. & 1 & 0 & 0 & 0 & 0 & 0 & - \\
\hline 10 & & n.t. & 4 & 2 & 1 & - & - & 2 & 3 \\
\hline 11 & & n.t. & 3 & 1 & 1 & - & - & 1 & 2 \\
\hline \multirow[t]{2}{*}{12} & & & & & & & & & \\
\hline & & n.t. & 5 & 1 & 1 & - & - & 1 & 4 \\
\hline 13 & & n.t. & 5 & 4 & 1 & - & - & 4 & 1 \\
\hline
\end{tabular}




\begin{tabular}{|c|c|c|c|c|c|c|c|c|c|}
\hline Link & Graph & $\mathrm{T}$ & N.C.U. & $\mathrm{M}$ & $\mu$ & $\mathrm{L}$ & $\lambda$ & $\mathrm{MB}$ & MMB \\
\hline 14 & & n.t. & 4 & 3 & 1 & - & - & 3 & 1 \\
\hline 15 & & t. & 4 & 0 & 0 & 3 & 1 & 3 & 1 \\
\hline 16 & & t. & 1 & 0 & 0 & 0 & 0 & 0 & - \\
\hline 17 & & t. & 3 & 0 & 0 & 2 & 1 & 2 & 1 \\
\hline 18 & & n.t. & 8 & 7 & 4 & - & - & 8 & 1 \\
\hline 19 & & n.t. & 3 & 1 & 1 & - & - & 1 & 2 \\
\hline 20 & & t. & 5 & 0 & 0 & 1 & 1 & 1 & 4 \\
\hline 21 & & n.t. & 7 & 6 & 3 & - & - & 6 & 1 \\
\hline 22 & & n.t. & 5 & 4 & 2 & - & - & 4 & 1 \\
\hline 23 & & n.t. & 6 & 5 & 3 & - & - & 5 & 1 \\
\hline 24 & & n.t. & 2 & 5 & 2 & - & - & 5 & 1 \\
\hline 25 & & n.t. & 2 & 3 & 1 & - & - & 3 & 1 \\
\hline
\end{tabular}




\begin{tabular}{|c|c|c|c|c|c|c|c|c|c|}
\hline Link & Graph & $\mathrm{T}$ & N.C.U. & $\mathrm{M}$ & $\mu$ & $\mathrm{L}$ & $\lambda$ & $\mathrm{MB}$ & MMB \\
\hline 26 & & $\mathrm{t}$. & 1 & 0 & 0 & 0 & 0 & 0 & - \\
\hline 27 & & t. & 1 & 0 & 0 & 0 & 0 & 0 & - \\
\hline 28 & & n.t. & 3 & 2 & 2 & - & - & 2 & 1 \\
\hline 29 & & n.t. & 2 & 2 & 2 & - & - & 2 & 1 \\
\hline 30 & & n.t. & 2 & 2 & 2 & - & - & 2 & 1 \\
\hline 31 & & n.t. & 3 & 3 & 2 & - & - & 3 & 1 \\
\hline 32 & & n.t. & 3 & 3 & 2 & - & - & 3 & 1 \\
\hline 33 & & n.t. & 4 & 3 & 2 & - & - & 4 & 1 \\
\hline 34 & & n.t. & 4 & 3 & 2 & - & - & 4 & 1 \\
\hline 35 & & n.t. & 4 & 3 & 2 & - & - & 4 & 1 \\
\hline 36 & & t. & 1 & 0 & 0 & 0 & 0 & 0 & - \\
\hline
\end{tabular}

This method can be also extended to such topologically trivial systems like [n]-rotaxanes. However, two conditions must be always accomplished. The first one deals with the analysis itself, which must be carried out with the embedded graphs ${ }^{20}$ or rigid representations. The second one concerns the stopper groups within such embedded graphs, which must be large enough, not to analyze the situations with pseudo-rotaxanes. ${ }^{21}$ Since Brunnian numbers $M=\mu=0$ for all compounds of this type, I propose to use new descriptors $\mathrm{L}$ and $\lambda$ (both from the word "link"), 
which would be complementary to $\mathrm{M}$ and $\mu$, respectively (Table 1). Analysis of [4]-rotaxane 15 gives three possibilities (Figure 5): (1) dumbbell-like unit 16 and three rings 9; (2) [2]-rotaxane 1 and two rings 9 and (3) [3]-rotaxane 17 and one ring 9 . The longest way of the decomposition of 15 lies on the way of the stepwise disconnection of all rings: $\mathbf{1 5} \rightarrow \mathbf{1 7} \rightarrow \mathbf{1} \rightarrow \mathbf{1 6}$. Thus, $\mathrm{L}=3$. The shortest decomposition is possible when the cut-disconnection-repairing sequence is applied directly to the axle. In this case $\lambda=1$ (Table 1 ).

The concept of sublinks seems to be too complex (and thus not the necessary one) in the cases of such mechanically bonded (at least partly) complexes as (hemi)carceplexes. ${ }^{8 c, 22}$ The simplest way to analyze such structures is to count the number of encapsulated small molecules within a shell of (hemi)carcerand without involving any cuts. The second and quite natural characteristic is the free energy barrier needed for the release of the encapsulated guest(s). An analogous energetic characteristic can be employed for the characterisation of the stability of anchoranes ${ }^{19}$ and foldamers ${ }^{23}$ together with the number of covalently built units, which compose such structures.

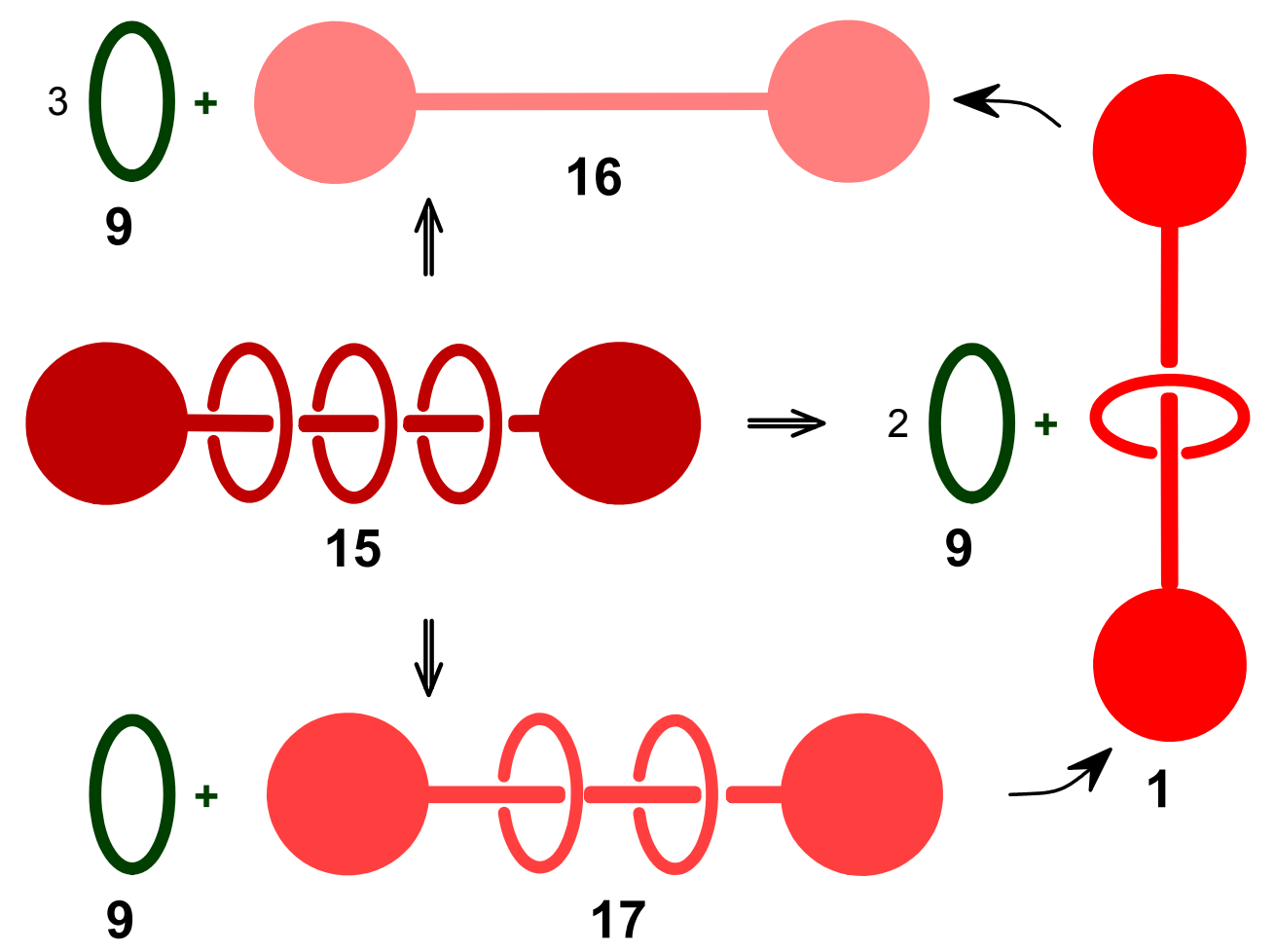

Figure 5. Analysis of [4]-rotaxane 15 (the embedded graphs ${ }^{20}$ or rigid representations are used in this case). 


\section{Basic differences between "composition" and mechanical connection of (sub)links}

It is important to stress, I deal here only with the "mechanical connections" of (sub)links, not with their "composition". There are two steps necessary for the last operation (Figure 6a): (1) breaking lines within each of the links, which are to be composed; (2) connection of the lines from links prepared in such a way that a new composite (or product) link appears. In this way two [2]-catenanes $\mathbf{2}$ can be composed only into one [3]-catenane $\mathbf{3}^{24}$

a)

2

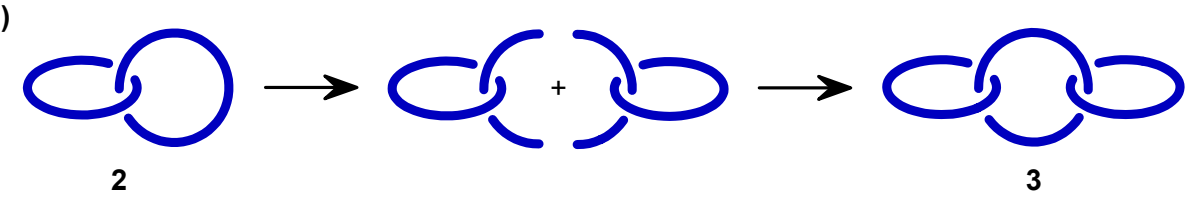

b)

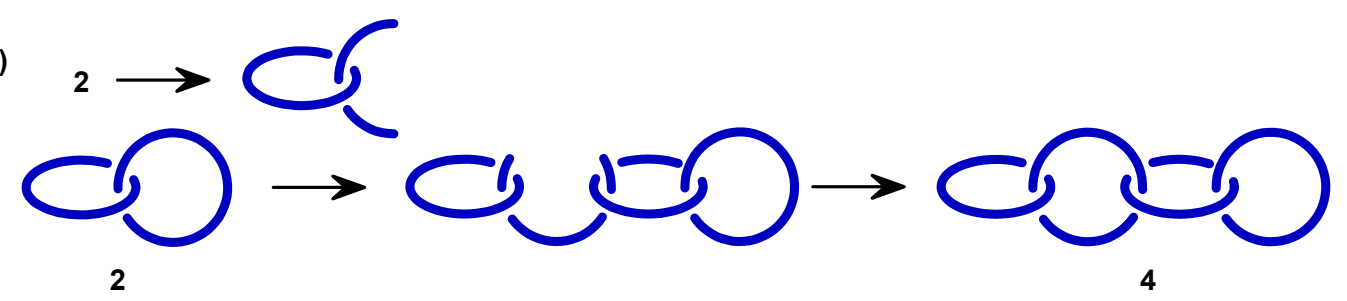

Figure 6. (a) Composition and (b) mechanical connection of two [2]-catenanes 2. This leads either to [3]- 3 or [4]-catenane $\mathbf{4}$, respectively.

In contrast to this, the mechanical bonding of two 2 requires three steps: 1) the breaking of one line within only one counterpart, ${ }^{25}$ ) entanglement of this open structure with the (sub)link we want mechanically to bind to and, finally, 3) repair of the line previously broken. Thus, the difference between these two approaches applied to the same links, is exactly one ring. The type of disconnections applied here for the analysis of links is reverse to the one shown in Figure $6 \mathrm{~b}$.

\section{On the numbers of ordinary mechanical bonds}

There are still some contradictions left in the literature towards the strict name of the connections within catenanes or rotaxanes and thus within similar structures. Some earlier works describe them as "topological bonds", ${ }^{26}$ though later this name was completely exchanged for the "mechanical" ones. The last name covers a much larger area of the compounds with such connections, since rotaxanes, (hemi)carcerates ${ }^{8 c, 22}$ and foldamers ${ }^{23}$ are the topologically trivial structures and thus their covalent units can not be hold by any of the "topological bonds" per se. ${ }^{27}$ The most rational way to count the numbers of such connections is to count the maximal possible disconnection sequences described above made within either of rings or of dumbbelllike units [in [n]-rotaxanes] to disconnect them. In the classical structures of the linear type $\mathbf{1}-\mathbf{4}$ 
the number of such "mechanical bonds" (MB) is equal to the number of cuts needed to separate completely the links and thus is equal either to $\mathrm{M}$ or L numbers (Table 1). For example, there is only one such bond within [2]-rotaxane 1 or [2]-catenane $\mathbf{2}$ present (Figure 1), however [3]- 3 and [4]-catenane 4 possess two and three MBs, respectively. ${ }^{28}$ On the other hand, the number of $\mathrm{MB}$ in these cases is for "1" less than the number of covalent units $n$ shown in the square brackets. One might even make a simple rule out of such examples, that $\mathrm{MB}=\mathrm{M}=n-1$. But the last rule with number $n$ does not work always and it would be even wrong to overestimate the meaning of it. On the other hand, the numbers $\mathrm{M}$ or L either reflect directly or are quite close to the real numbers of the mechanical bonds. In the cases of bis-[2]- (5) and bis-[3]- (6) catenanes ${ }^{9 \mathrm{~b}}$ $\mathrm{MB}=\mathrm{M}$ and are 2 and 4 , respectively.

However, the situation in 7 is additionally complicated due to the fusion of macrocycles (Figure 2). Let us look first at the graph of the normal cyclic [8]-catenane 18 (Figure 7). Each ring in this structure is mechanically connected with two neighbouring rings (of a different colour) and seven disconnection sequences are needed to disconnect them step-by-step. Thus, $M$ $=7$ (Table 1). However, the number of mechanical bonds is equal to eight in this case $\mathrm{MB}=8$, since the very first mechanical disconnection leads to loosing two of such bonds. In other words, $\mathrm{MB}=\mathrm{M}+1$ for the cyclic structures.

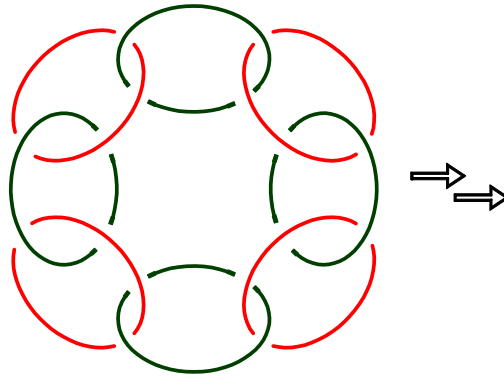

18
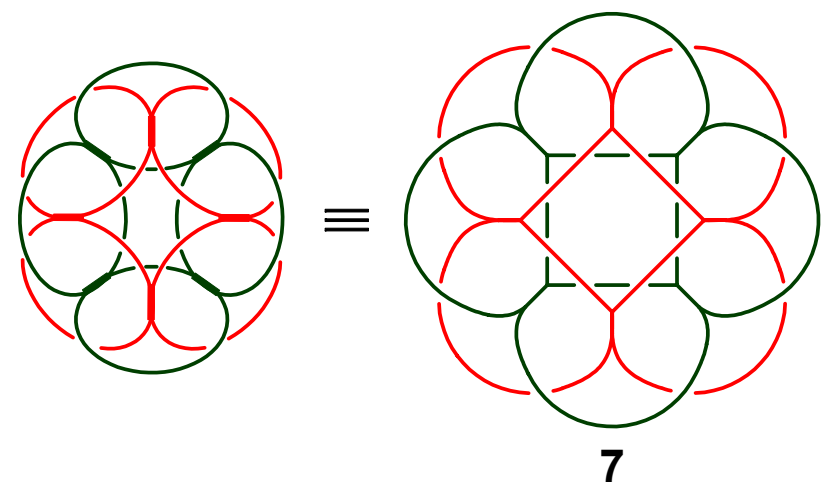

Figure 7. The topological similarities between cyclic [8]-catenanes 7 and 18. The arrows represent "formal chemical fusion" either of the "red" or of the "green" rings.

If we consider purely chemical annelation of each "red" macrocycle with two "red" neighbouring rings in 18 (and thus fusion of each "green" macrocycle with two "green" neighbours), we end up exactly with the graph of the calixarene-based cyclic [8]-catenane 7. Such formal annelation does not change the number of mechanical connections per se, since it does not touch them. Thus $\mathrm{MB}=\mathrm{M}+1=8$ also in this case. From the comparison of $\mathbf{7}$ and 18, one can easily conclude, that the number of mechanical bonds persists whether rings are fused with each other or not. Thus, if any system with some annelated rings is to be analyzed for the number of mechanical connections, it is wise to analyze it as if the annelation (or perhaps other connections $^{29}$ ) would not exist. 
The counting of the mechanical bonds in [n]-rotaxanes is similar. Within the already discussed example 15 (Figure 5), $\mathrm{MB}=\mathrm{L}=3$. There are, however, very special cases of [n]rotaxanes $^{30}$ like the ones made from cucurbit[n]urils. ${ }^{31}$ These compounds possess relatively complicated structure. If the proposals about the cutting numbers $L$ and $\lambda$ apply to the known [2]-rotaxanes of this type, then one would find $L=2$, since minimum two cuts are needed within the cucurbit[n]urils to disconnect them from the dumbbell. However, there is only one mechanical bond present. Thus, $\mathrm{MB}=(\mathrm{L}-1) \mathrm{x}$, where $\mathrm{L}$ is the new complement to the Brunnian numbers and $\mathrm{c}$ is the number of cucurbit[n]uril units in such [n]-rotaxanes. It would be wise to act analogously in other similar examples.

While numbers $\mathrm{M}$ and $\mathrm{L}$ are closely related to the numbers of the molecular bonds, the number $\mu$ is rather related to the number of sublinks of the first order (see later). It is important to note, that the additional intertwining between the mechanically connected units (e.g. rings) does not alter any of the properties of the mechanical connection in this purely theoretical investigation, since it does not change any of the Brunnian numbers.

\section{Multiple mechanical bonds}

There are some possibilities, where more than two covalent units are connected with each other via the only one mechanical connectivity in such a way that $\mathrm{M}=\mu=1$ (Brunnian property), that means only one disconnection sequence is sufficient to disconnect rings in these structures. Some examples of them are met already among Borromean rings $\mathbf{1 1}$ or 12, see also 19 (Figure 8). Some examples like [5]-rotaxane 20 (Figure 8), ${ }^{32}$ which had been obtained under a certain approximation, obey quasi-Brunnian property $(\mathrm{L}=\lambda=1) .{ }^{33}$ Such cases I suggest to classify as the ones with the multiple mechanical bonds. The connections in such links having three, four or five units I propose to call as double, triple and quadruple mechanical bonds, respectively, since there are one, two or three units more than are present in the simplest cases like $\mathbf{1}$ and $\mathbf{2}$ with single mechanical bonds. The highest multiplicity of mechanical bonds of all structures met in this article, is indicated in Table 1 as MMB. The multiplicity of the mechanical bond in all Borromean rings is actually higher than one. The interesting example can be $\mathbf{8}$, which demonstrates the highest MB-multiplicity of 5, since there is still the possibility to disconnect the link in one "disconnection-operation" (Table 1). In strike contrast to this example, molecular necklaces like 13 and [n]-rotaxanes of the type 15 have several single mechanical connections and none of them with the higher multiplicity. There is also the possibility to "chop" $\mathbf{8}$ step-bystep via 10 and 11 since $M=3$ or using the alternative way via 12 (Figure 3). There is the double mechanical bond between $\mathbf{1 0}$ and two rings $\mathbf{9}$ (that yields 8), while there is the single one between 11 and one 9 (that yields 10) and between 12 and one 9 (that gives 8). The overall number of the mechanical bonds in this case is equal to four, since there are four different possibilities to represent $\mathbf{8}$ as the sum of sublinks (Figure 3b). In the same time $\mathbf{1 0}$ possesses two mechanical bonds. 


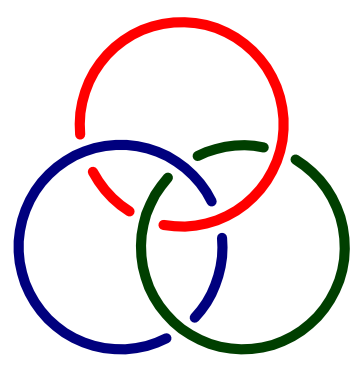

19

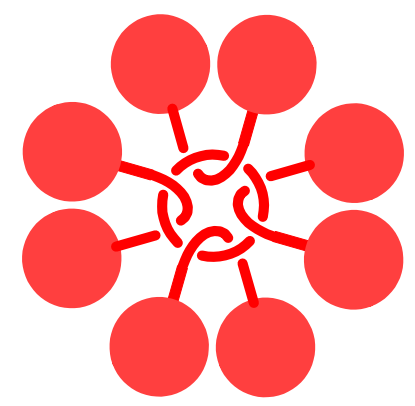

20

Figure 8. Two additional examples with double (19) and guadruple (20) mechanical bonds.

\section{Hierarchy of (sub)links}

As it was already pointed out, sublinks can be not only topologically non-trivial or trivial, but can also have the different numbers of covalent units present and thus the different number(s) of mechanical bonds: the triple one and the single one between the sublink $\mathbf{1 1}$ and one ring $\mathbf{9}$. It is interesting to note, the double mechanical bond in $\mathbf{1 1}$ is not counted in these two last examples, since 11 is not an independent link. Any attempt to disconnect the rings "1" (in blue) from 11 implemented in $\mathbf{8}$ or $\mathbf{1 0}$, leads immediately to the complete disconnections of these larger structures. I propose to classify (sub)links into different orders depending on the number of mechanical bonds present. For example, the (sub)links with zero mechanical bonds belong to the "zero order", while the ones having one, two (or higher) number of mechanical bonds belong to the first, second (or higher) orders, respectively.

Let us look once again at $\mathbf{1 8}$ and 7. The shortest way to disconnect $\mathbf{1 8}$ is to cut either "red" or "green" macrocycles, that means $\mu=4$ (Figure 9). There are at least twenty one possibilities to represent 18 as the sum of sublinks (Table 2). Some of the most obvious are: (1) four [2]catenanes, which are connected with each other via the mechanical bonds in the cyclic way; (2) two [3]- $\mathbf{3}$ and one [2]-catenane $\mathbf{2}$ in the cyclic arrangement cyclo[3 $+\mathbf{3}+\mathbf{2}+$ ]; or (3) two sublinks of second order $\mathbf{3}$ and two sublinks of zero order $\mathbf{9}$ in the arrangement cyclo[$[\mathbf{9}+\mathbf{3}+\mathbf{9}+$ $\mathbf{3}+]$ or cyclo $[\mathbf{9}+\mathbf{9}+\mathbf{3}+\mathbf{3}+]$. However, such different regioisomeric placements are not taken further into account, since they might lead to the endless possibilities even in 18. The next logical possibilities include the sublinks of the higher orders like [4]- 4, [5]- 22, [6]- 23, [7]- 21, and acyclic [8] -catenanes (Figure 9). The complete analysis of all links with at least two mechanical bonds met here, are summarized in Table 2. One could even think, $\mu$ or $\lambda$ might correspond to the number of the sublinks of the first order, like in this case, but it is not always like this. For example, $\mu$ is always equal to 1 for all molecular necklaces as well as $\lambda=1$ for [n]rotaxanes of the general formulae 15, which are of the higher orders by the definition. These numbers are very sensible also to the annelation present. For instance, 7 has $\mu=3$ (Figure 9b), in contrast to $\mathbf{1 8}$, due to the alternative way of the disconnection of this link. 
a)
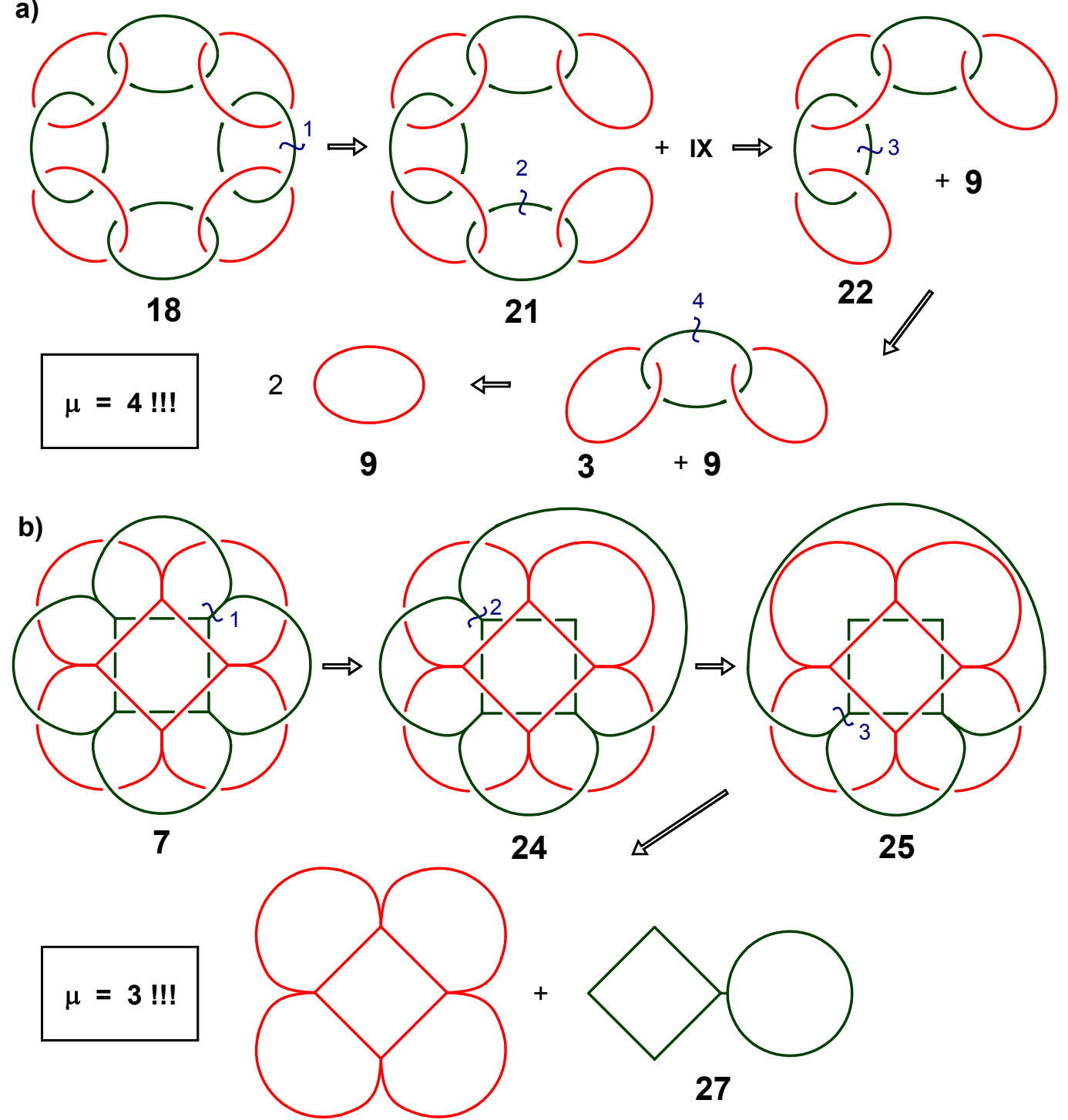

26

Figure 9. The shortest decompositions of two different cyclic [8]-catenanes. The numbers $\mu$ are indicated in these cases. 
Table 2. Structure of links in terms of the sum of sublinks (all possibilities are shown for the structures with at least two mechanical bonds)

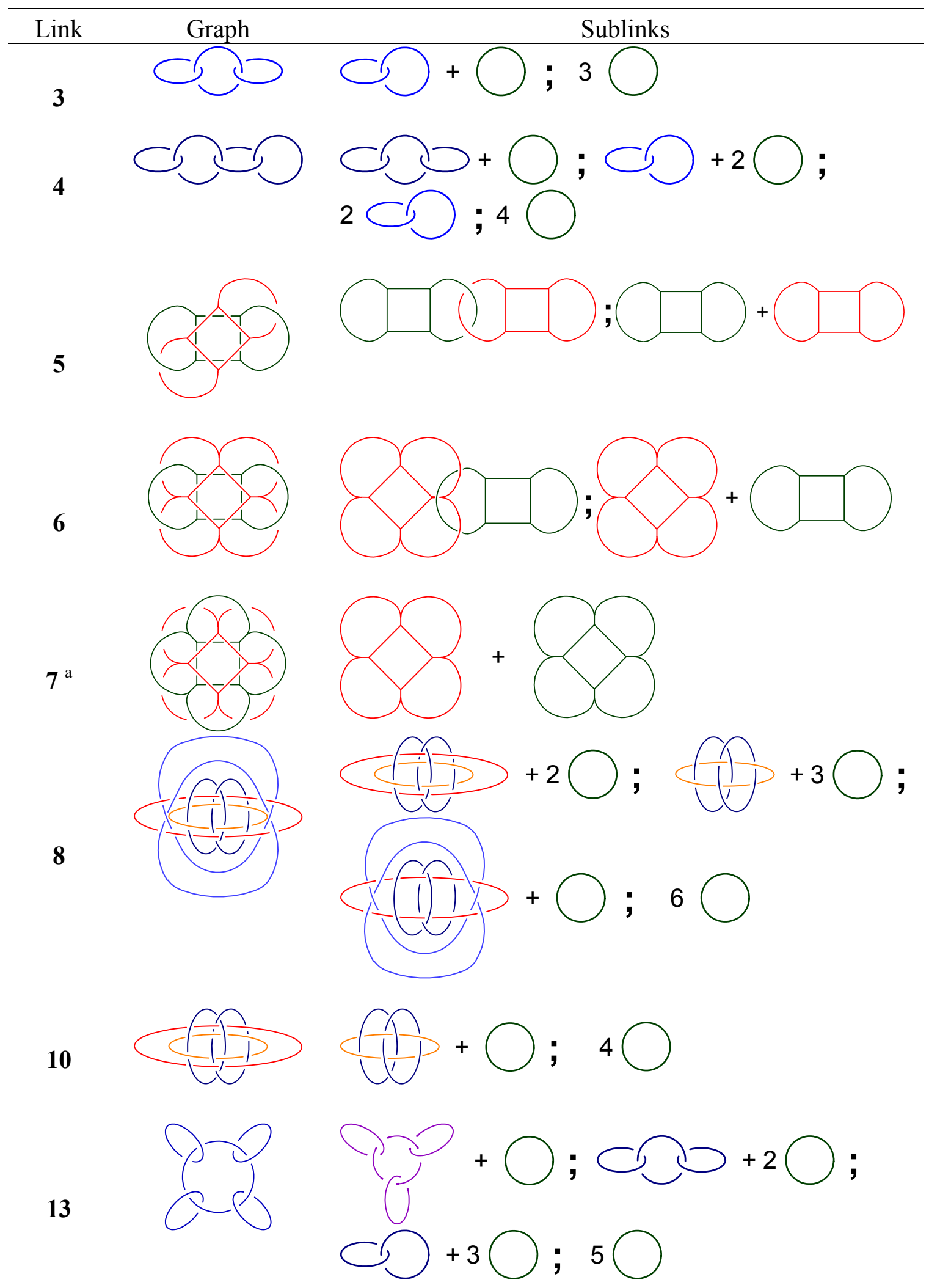




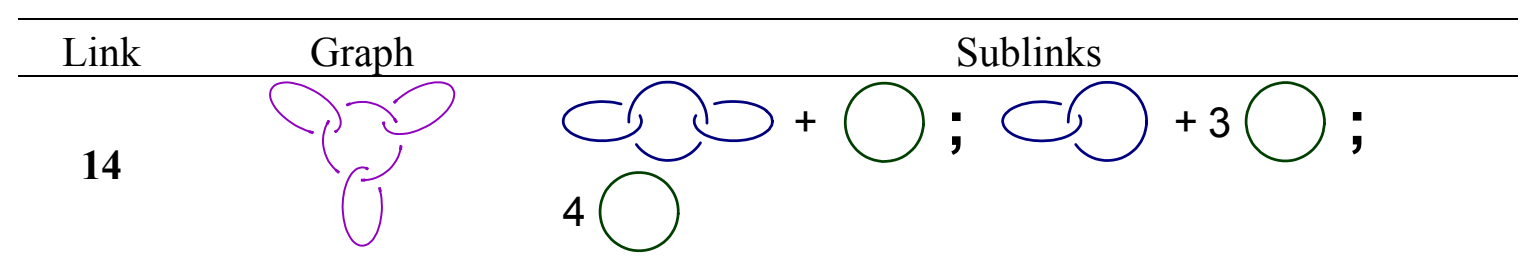

15

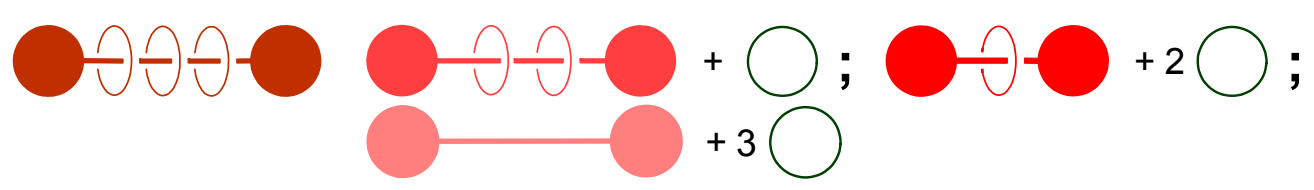

17

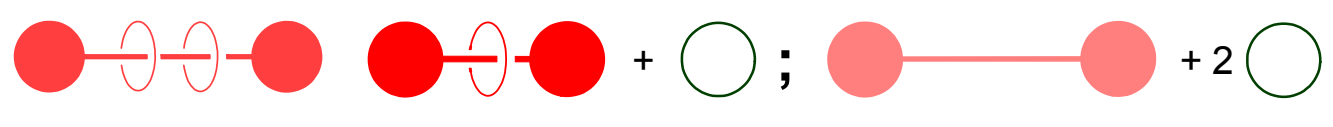

18

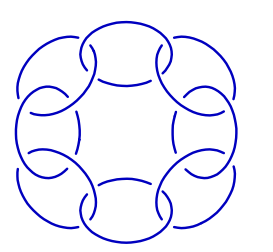

(O)

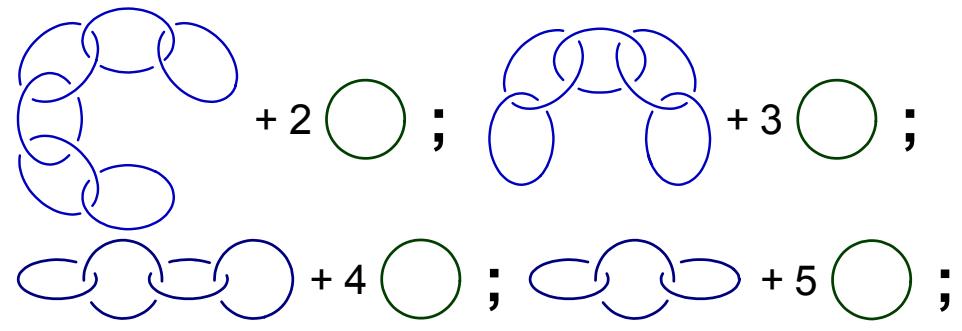

$\square+6 \bigcirc: 8 \bigcirc ;$

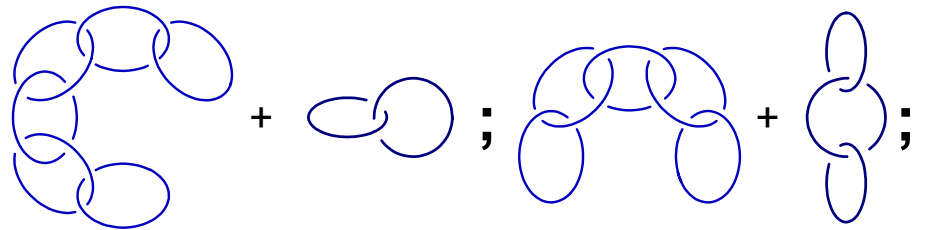

$8-0+0$;

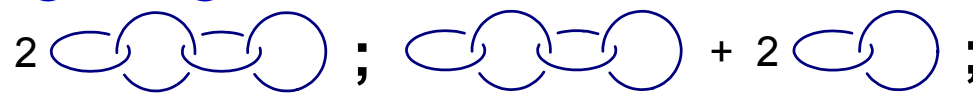

$0-6+C+$

$0+6+20$;

$20+$

$2 \bigcirc 0+2 \bigcirc$; 


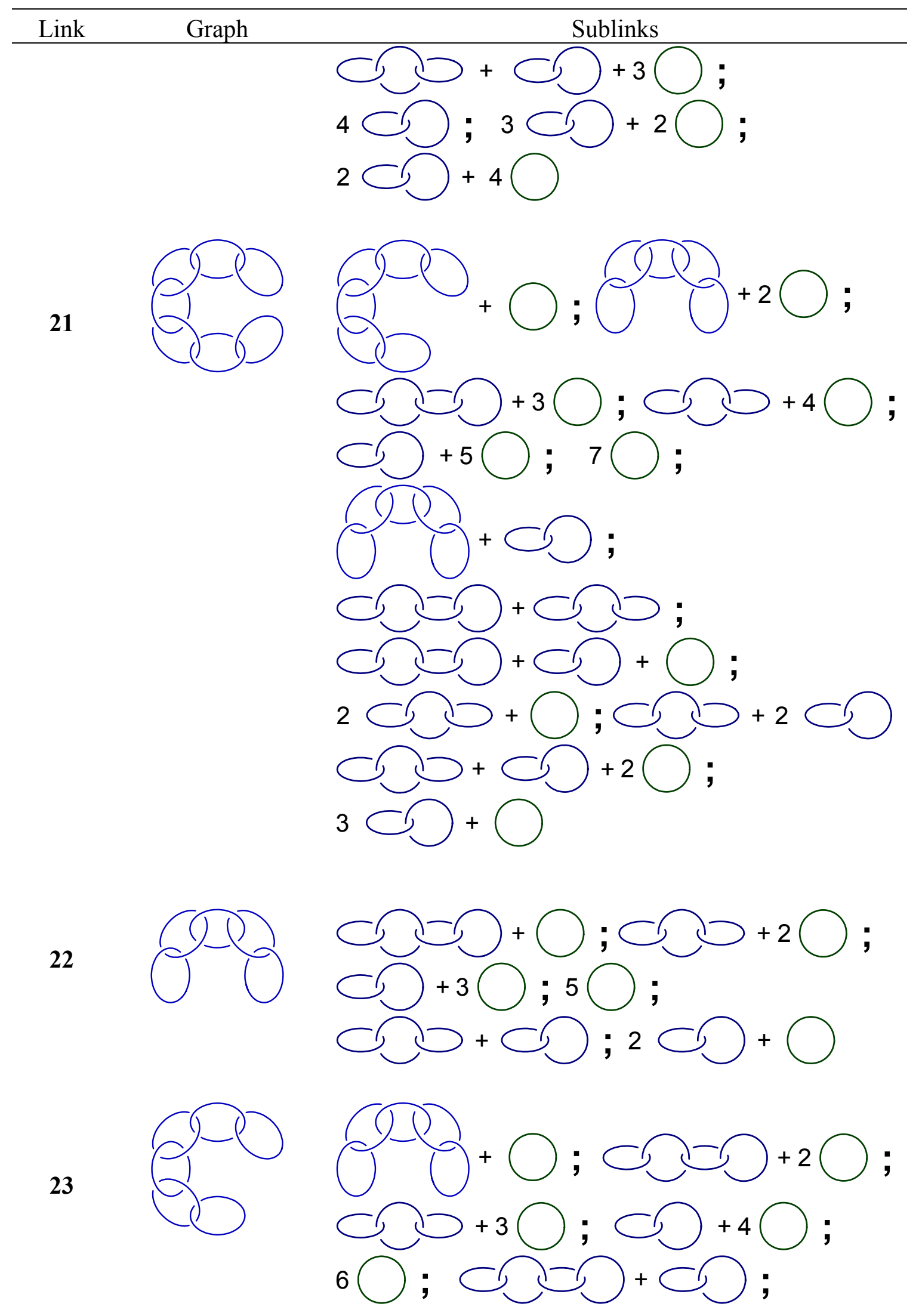




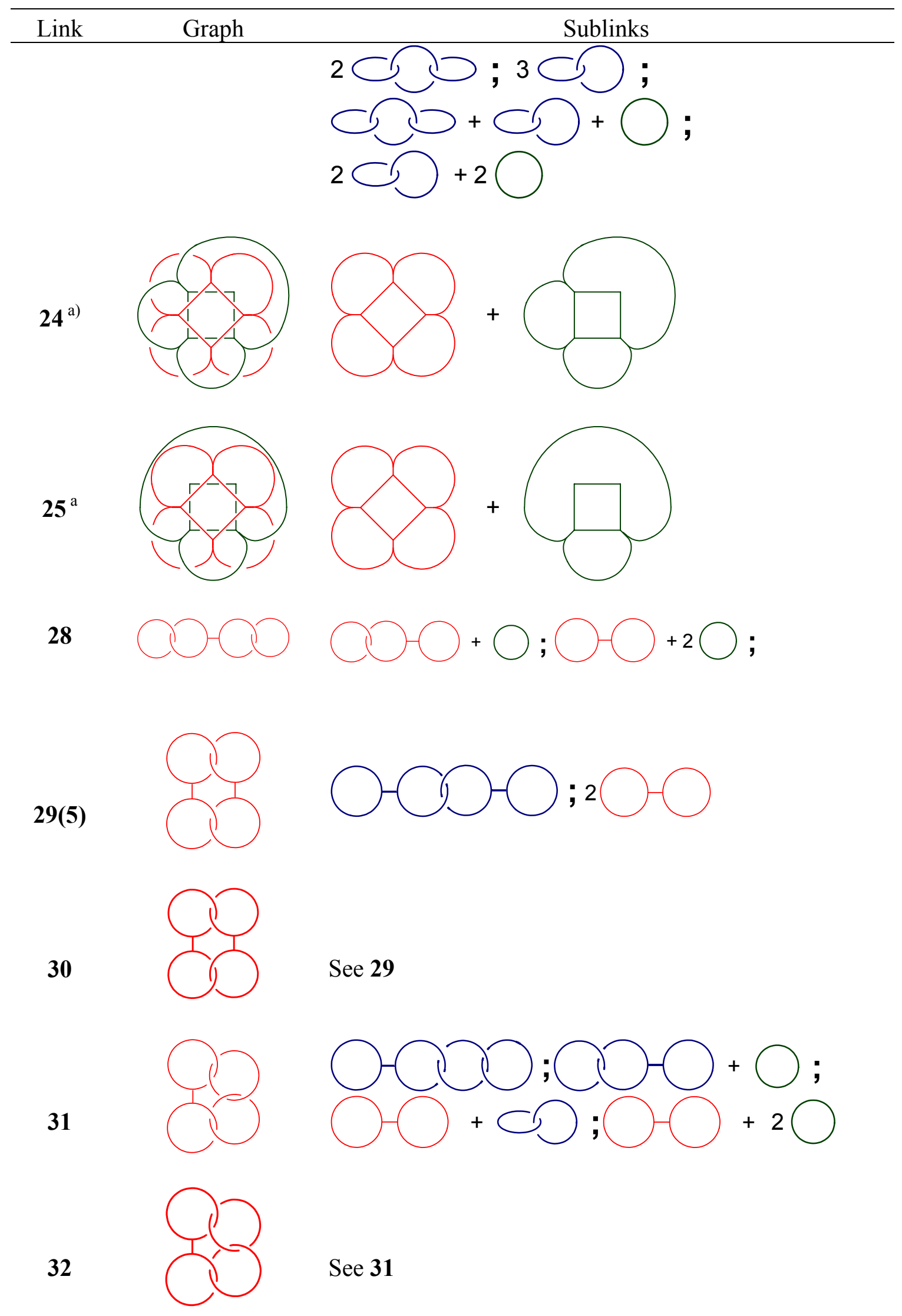




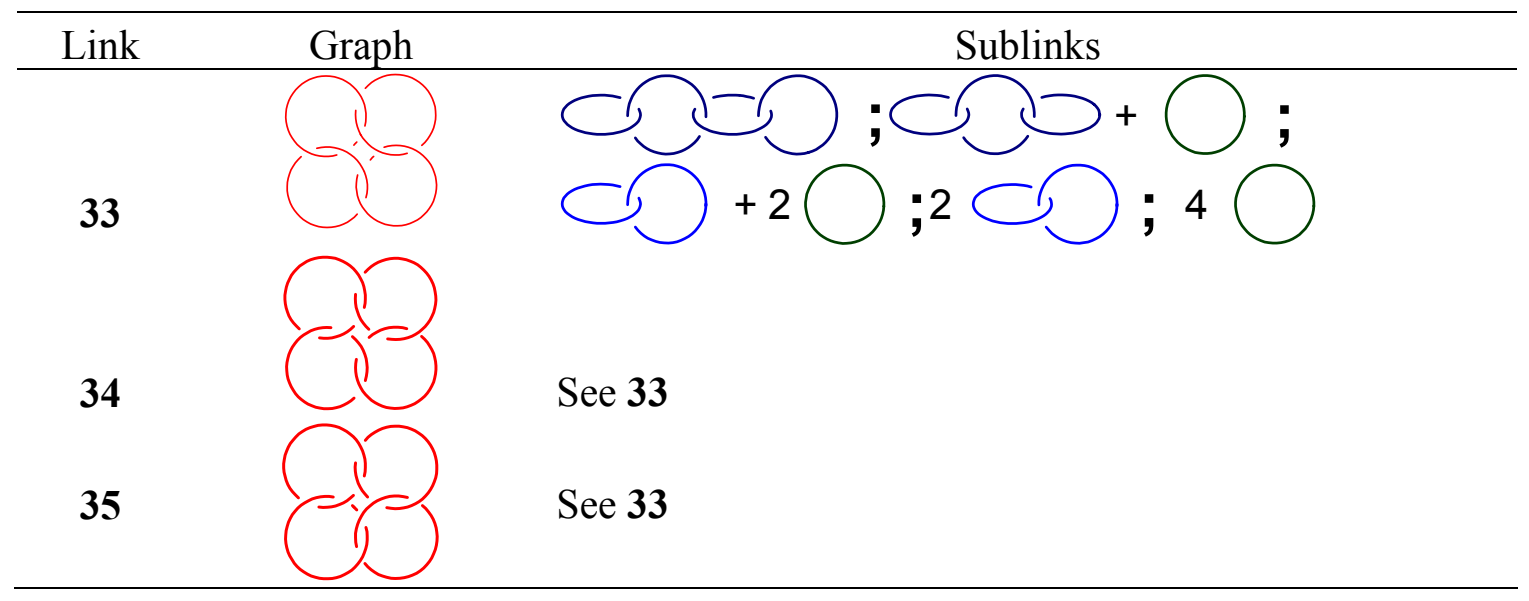

${ }^{a}$ The intermediate possibilities with one or several mechanical bonds are not shown due to the size limits of such small structural presentations.

\section{Sublinks as building blocks in construction of more complex structures}

The point of view at the composition of complex topologically non trivial (and related) systems proposed here, gives at hand the possibility to combine sublinks in the constructive and very logical way to derive more complex systems out of the simplest building blocks. As only one example, [2]-catenane $\mathbf{2}$ is taken for such purpose (Figure 10) and the derivative structures 4, 28 - 35 are constructed via the building either new mechanical or covalent bonds. I applied two conditions for such combinations: (1) only two $\mathbf{2}$ are combined; (2) one ring of one $\mathbf{2}$ can build only one either mechanical or covalent bond to only one ring of the second $2 .^{34}$ The symmetries of the structures obtained, are indicated (Figure 10). One or two of such covalent connections between 2 leads to the structures 28 - 30, which in the strict sense would be named either [3]- or [2]-catenanes, depending on the number of the covalent units connected mechanically. The authors of $9 \mathrm{a}$ would call these structures, most probably, as bis-[2]-catenanes. The structure similar to 29 but having four covalent connectivities (5) instead of only two, has been already examined. It should be noted, there is actually one additional combination with $\mathrm{C}_{2 \mathrm{~h}}$ symmetry (30) possible. Only one or four mechanical connectivities between 2 leads either to linear [4]- 4 or cyclic [4]-catenanes 33 - 35, respectively. As one can see, there are three symmetrically different combinations possible in the last case. It is worth of noting, that one mechanical and one covalent connectivities lead to [3]-catenanes $\mathbf{3 1}$ and 32. As you can see, the nomenclature possibilities are already exhausted even with such simple combinations between only two [2]catenanes 2.

Such approach in construction of more complex structures can be obviously applied also to the topologically trivial systems. 


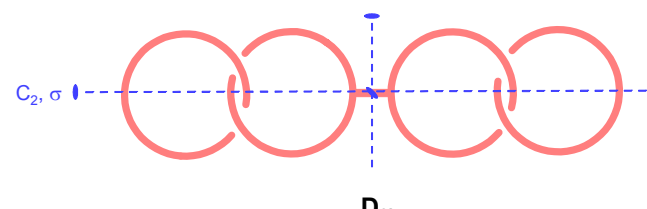

$D_{2 h}$

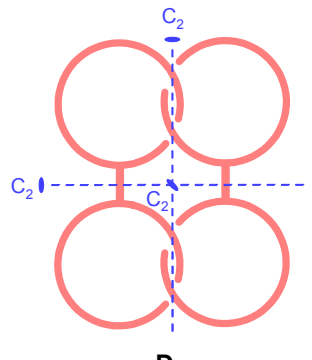

$\mathrm{D}_{2}$

29 (5)

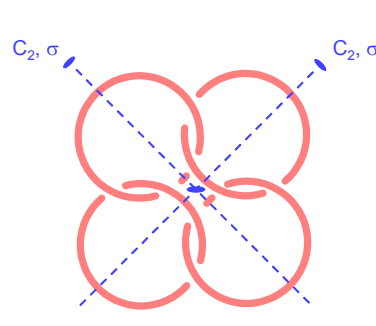

$\mathrm{D}_{2 \mathrm{~h}}$

33
28

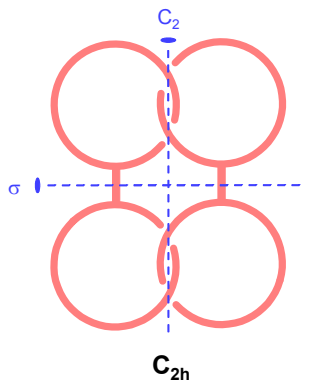

30

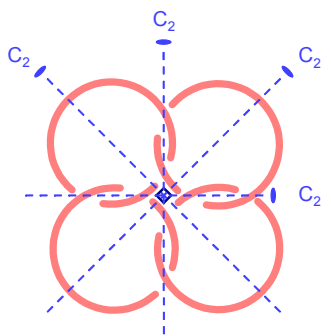

$\mathrm{D}_{4}$

34

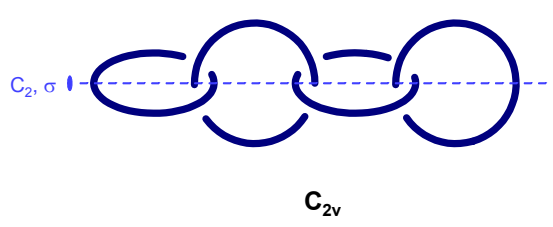

4

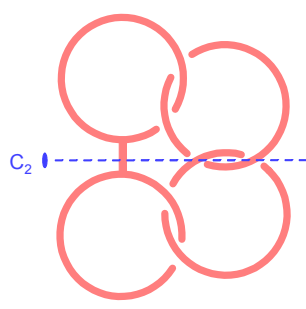

$\mathrm{C}_{2}$

31

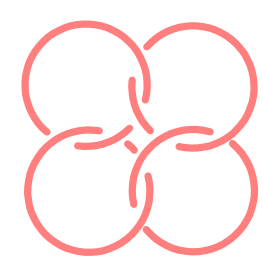

$\mathrm{C}_{1}$

35

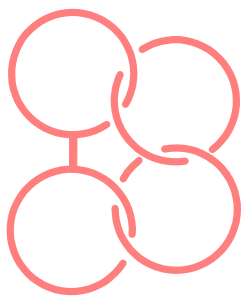

$\mathrm{C}_{1}$

32

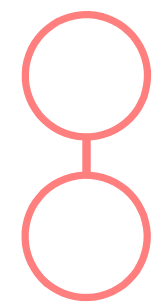

36

Figure 10. The covalent and/or mechanical connectivities of two [2]-catenanes 2.

\section{Proposal for nomenclature of the mechanically built systems}

It is very clear that structural formulae are still the best way to represent the constitution of mechanically bound species. Nevertheless, the existing contradictions within the existing nomenclature recommendations should be solved with the help of the new recommendations or ideas. There should be always the possibility to use the old rules for the simplest cases of "mechanically built" structures like 1 - 4. The usual rules used for description of knots, Borromean rings ${ }^{35}$ and simple molecular necklaces ${ }^{18}$ or even daisy chaines ${ }^{36}$ should also remain, unless they not became useless in these cases also. Only one digit in the square brackets of the names of mechanically bound compounds, do not represent good enough the mechanical connections in more complicated structures than in $\mathbf{1}$ - 4. To answer the question if the new nomenclature should be rather applied, than the old one, I suggest to answer the question if the number of mechanically bound rings or rings and dumbbells are equal to the number of covalent units present (Figure 11). If yes, most probably the old rules can be still applied (with the exception of 20 with only one quadruple mechanical bond). If not, then sublinks are involved in larger covalent units and the new names will reflect the structure better than the old ones and 
thus they should be applied. One can discuss what should be actually mentioned together with the name of structures: (1) the number of mechanical bonds, (2) their multiplicities or (3) the number of the covalent units present or, perhaps, (4) the number of mechanically linked rings or rings and dumbbells. I am sure, four digits are sufficient for the unique description of different mechanically built molecules. Taking the number of mechanical bonds (1) is of the higher priority for the mechanically bound compounds. Then, the highest multiplicity of the mechanical bond(s) (2) should be indicated, if it is higher than 1. In the simplest cases it might be omitted. The next characteristic, which should be indicated, is the number of covalent units (3) in the whole assembly. These characteristics should be separated via slashes (Figure 11). Their presence will thus show if the new rules are applied. When we deal only with the single mechanical bonds, it would be wise to omit this indication (leaving two slashes that would indicate this parameter is omitted), like it is done in the cases of 5, 7, 28 and $\mathbf{3 1}$ (Figure 11). The letter "c" in the name of 7 stems from "cyclic", that would be helpful for the understanding of the structure of such cyclic systems. Old and new names are also summarized in Table 3 also for the cases, when it must not be necessary used. The last digit I would recommend to indicate, is the number of the mechanically linked rings or rings and dumbbells (4). This must be stated, when their number is different than the number of covalent units (3). The number (4) should come after (3) separated by comma.

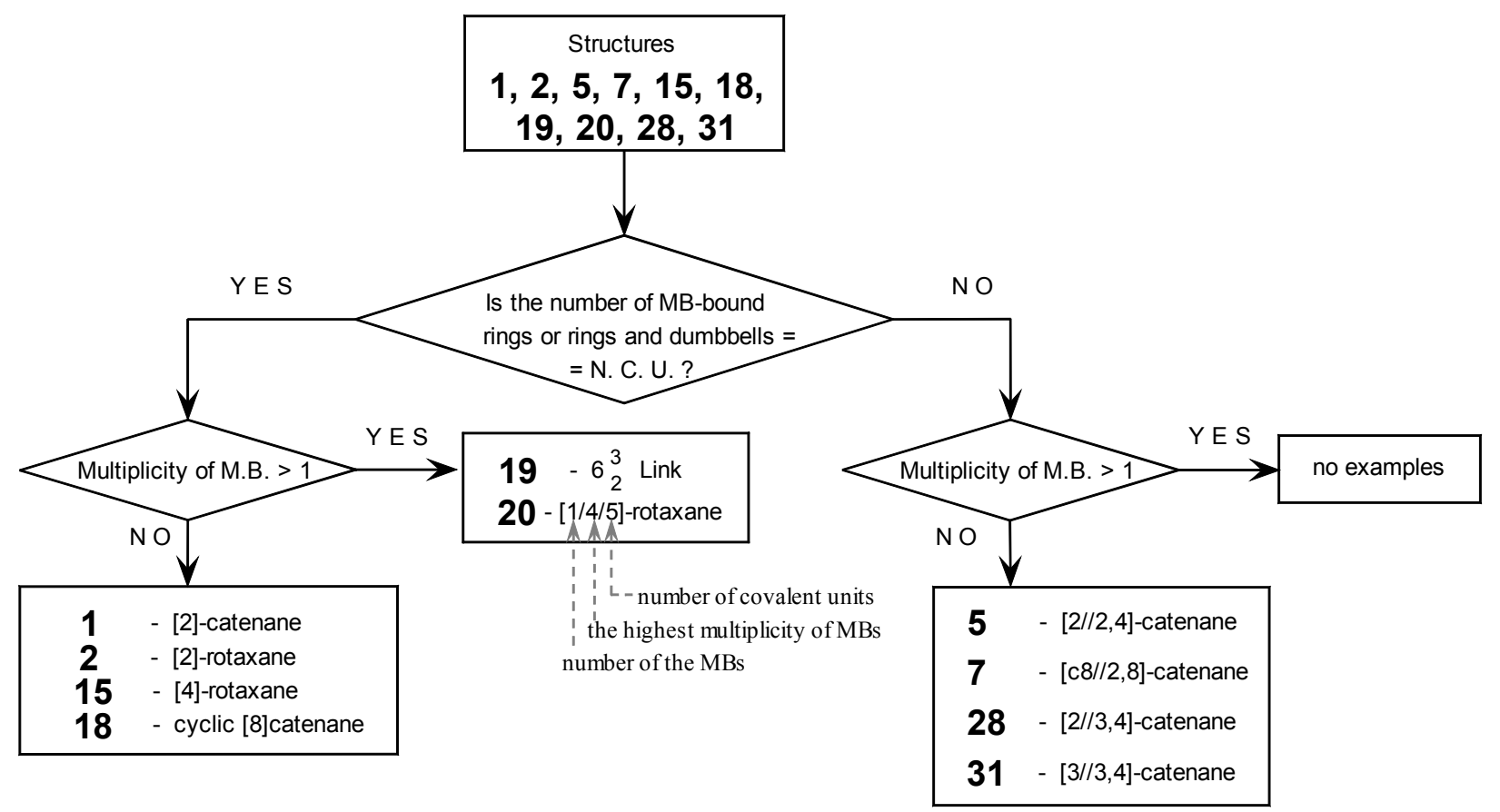

Figure 11. Algorithm for naming the mechanically bound molecules. "N. C. U." is the number of covalent units. "M.B." means "the mechanical bond". The second digit in the names of 5, 7, 28 and 31 (multiplicity of $\mathrm{MB}$ ) is omitted for the sake of simplicity of the names due to the normal first order of the mechanical connections in these cases. 
Table 3. Old and new names for the mechanically built molecules met in this article

\begin{tabular}{|c|c|c|c|}
\hline Link & Old name & New name & $A^{a}$ \\
\hline 1 & [2]-rotaxane & {$[1 / / 2]$-rotaxane $^{b}$} & $\mathrm{n}$ \\
\hline 2 & [2]-catenane & {$[1 / / 2]$-catenane $^{b}$} & $\mathrm{n}$ \\
\hline 3 & [3]-catenane ([3]-MN) & {$[2 / / 3]$-catenane $^{b}$} & $\mathrm{n}$ \\
\hline 4 & [4]-catenane & {$[3 / / 4]$-catenane ${ }^{b}$} & $\mathrm{n}$ \\
\hline 5 & "bis-[2]-catenane" & {$[2 / / 2,4]$-catenane } & $\mathrm{y}$ \\
\hline 6 & "bis-[3]-catenane" & {$[4 / / 2,6]$-catenane } & $\mathrm{y}$ \\
\hline 7 & "cyclic [8]catenane" & {$[\mathrm{c} 8 / / 2,8]$-catenane } & $\mathrm{y}$ \\
\hline 8 & 6-Borromean ring & {$[4 / 5 / 6]$-Borromean ring ${ }^{b}$} & $\sim$ \\
\hline 10 & 4-Borromean ring & {$[2 / 3 / 4]$-Borromean ring $b$} & $\sim$ \\
\hline 11 & 3-Borromean ring & {$[1 / 2 / 3]$-Borromean ring $b$} & $\sim$ \\
\hline 12 & 5-Borromean ring & {$[1 / 4 / 5]$-Borromean ring ${ }^{b}$} & $\sim$ \\
\hline 13 & [5]-molecular necklace & {$[4 / / 5]-$ molecular necklace ${ }^{b}$} & $\mathrm{n}$ \\
\hline 14 & [4]-molecular necklace & {$[3 / / 4]-m o l e c u l a r$ necklace ${ }^{b}$} & $\mathrm{n}$ \\
\hline 15 & [4]-rotaxane & {$[3 / / 4]$-rotaxane ${ }^{b}$} & $\mathrm{n}$ \\
\hline 17 & [3]-rotaxane & {$[2 / / 3]$-rotaxane ${ }^{b}$} & $\mathrm{n}$ \\
\hline 18 & cyclic $[8]$-catenane & {$[\mathrm{c} 8 / / 8]$-catenane ${ }^{b}$} & $\mathrm{n}$ \\
\hline 19 & 3-Borromean ring & {$[1 / 2 / 3]$-Borromean ring ${ }^{b}$} & $\sim$ \\
\hline 20 & [5]-rotaxane & {$[1 / 4 / 5]$-rotaxane ${ }^{b}$} & $\mathrm{y}$ \\
\hline 21 & [7]-catenane & {$[6 / / 7]$-catenane ${ }^{b}$} & $\mathrm{n}$ \\
\hline 22 & [5]-catenane & {$[4 / / 5]$-catenane ${ }^{b}$} & $\mathrm{n}$ \\
\hline 23 & [6]-catenane & {$[5 / / 6]$-catenane } & $\mathrm{n}$ \\
\hline 24 & [5]-catenane & {$[\mathrm{c} 5 / / 2,6]$-catenane } & $\mathrm{y}$ \\
\hline 25 & [3]-catenane & {$[\mathrm{c} 3 / / 2,4]$-catenane } & $\mathrm{y}$ \\
\hline 29 & "bis-[2]-catenane" & {$[\mathrm{c} 2 / / 2,4]$-catenane } & $\mathrm{y}$ \\
\hline 30 & "bis-[2]-catenane" & {$[\mathrm{c} 2 / / 2,4]$-catenane } & $\mathrm{y}$ \\
\hline 31 & [3]-catenane & {$[3 / / 3,4]$-catenane } & $\mathrm{y}$ \\
\hline 32 & [3]-catenane & {$[3 / / 3,4]$-catenane } & $\mathrm{y}$ \\
\hline 33 & cyclic [4]-catenane & {$[\mathrm{c} 4 / / 4]$-catenane ${ }^{\mathrm{b}}$} & $\mathrm{n}$ \\
\hline 34 & cyclic [4]-catenane & {$[\mathrm{c} 4 / / 4]$-catenane ${ }^{\mathrm{b}}$} & $\mathrm{n}$ \\
\hline 35 & cyclic [4]-catenane & {$[\mathrm{c} 4 / / 4]$-catenane ${ }^{\mathrm{b}}$} & $\mathrm{n}$ \\
\hline
\end{tabular}

a Answer to the question whether the new name represents better the structure of a given system; "n" - means "not", "y" - means "yes", " " - means 50/50, in the opinion of the author; ${ }^{b}$ the numbers of interlocked rings or rings and dumbbells are omitted, since they are equal to the numbers of covalent units in the assembly. 


\section{Conclusions}

The attempt is made, to develop further the concept of sublinks, which had been coined once in the connection with Borromean rings. ${ }^{11}$ Sublinks are constitutional units of more complex links, which can be both topologically non-trivial (catenanes, molecular necklaces, etc.) and trivial ones (rotaxanes). Sublinks can be thus differentiated by the topology (trivial or non-trivial one), the number of covalent units or the number of mechanical bonds present. The last characteristic differentiates the sublinks into the ones of the zero, first, second and so on orders. It is also demonstrated, the mechanical bonds per se can be also of different multiplicities depending on the number of covalent units held together via such connection. The analysis of mechanically bound structures in terms of the sum of sublinks, demonstrates the certain inconsistency of the existing nomenclature recommendations for relatively complex structures. That is why the new recommendations have been developed, which highlight rather the number of the mechanical bonds present [, their highest order], and the number of the interlocked rings or rings and dumbbells than only the number of covalent units connected in this way.

\section{Acknowledgements}

I thank Volker Böhmer (Mainz, Germany), Abteilung für Lehramtskandidaten der Chemie (Mainz, Germany) and Institut für Organische Chemie (Mainz, Germany) for their generous support during my stay at Johannes - Gutenberg University. The work was supported by the Deutsche Forschungsgemeinschaft ("eigene Stelle": Vy 6/1-3) and German State (ALG I).

\section{References and notes}

1. (a) Crowley, J. D.; Goldup, S. M.; Lee, A.-L.; Leigh, D. A.; McBurney, R. T. Chem. Soc. Rev. 2009, 38, 1530. (b) Balzani, V.; Credi, A.; Venturi, M. Chem. Soc. Rev. 2009, 38, 1542. (c) Coronado, E.; Geviña, P.; Tatay, S. Chem. Soc. Rev. 2009, 38, 1674. (d) Mullen, K. M.; Beer, P. D. Chem. Soc. Rev. 2009, 38, 1701. (e) Stoddart, J. F. Chem. Soc. Rev. 2009, 38, 1802. (f) Molecular Catenanes, Rotaxanes and Knots; Sauvage, J.-P. and DietrichBuchecker, C. Eds. Wiley-VCh, Weinheim, 1999.

2. Godt, A. Eur. J. Org. Chem. 2004, 1639.

3. (a) Sauvage, J.-P. Chem. Commun. 2005, 1507. (b) Wenz, G.; Han, B. H.; Müller, A. Chem. Rev. 2006, 106, 782.

4. (a) Raymo, F. M.; Stoddart, J. F. Chem. Rev. 1999, 99, 1643. (b) Bogdan, A.; Rudzevich, Y.; Vysotsky, M. O.; Böhmer, V. Chem. Commun. 2006, 2941.

5. (a) Dietrich-Buchecker, C.; Sauvage, J.-P. Angew. Chem., Int. Ed. Engl. 1989, 28, 189. (b) Dietrich-Buchecker, C.; Sauvage, J.-P. Chem. Commun. 1997, 2053. (c) Safarowski, O.; 
Nieger, M.; Fröhlich, R.; Vögtle, F. Angew. Chem. Int. Ed. 2000, 39, 1616.

6. Chichak, K. S.; Cantrill, S. J.; Pease, A. R.; Chiu, S. H.; Cave, G. W. V.; Atwood, J. L.; Stoddart, J. F. Science 2004, 304, 1308.

7. (a) Green, J. E.; Choi, J. W.; Boukai, A.; Bunimovich, Y.; Johnston-Halperin, E.; Delonno, E.; Luo, Y.; Sheriff, B. A.; Xu, K.; Shin, Y.-S.; Tseng, H.-R.; Stoddart, J. F.; Heath, J. R. Nature 2007, 445, 414. (b) Mendes, P. M.; Flood, A. H.; Stoddart, J. F. Appl. Phys. A 2005, $80,1197$.

8. (a) Hubin, T. J.; Busch, D. H. Coord. Chem. Rev. 2000, 200-202, 5. (b) Vickers, M. S.; Beer, P. D. Chem. Soc. Rev. 2007, 36, 211. (c) Jasat, A.; Sherman, J. Chem. Rev. 1999, 99, 931.

9. (a) Vysotsky, M. O.; Bolte, M.; Thondorf, I.; Böhmer, V. Chem Eur. J. 2003, 9, 3375. (b) Wang, L.; Vysotsky, M. O.; Bogdan, A.; Bolte, M.; Böhmer, V. Science 2004, 304, 1312. (c) Molokanova, O.; Bogdan, A.; Vysotsky, M. O.; Bolte, M.; Ikai, T.; Okamoto, Y.; Böhmer, V. Chem Eur. J. 2007, 13, 6157. (d) Gaeta, C.; Vysotsky, M. O.; Bogdan, A.; Böhmer, V. J. Am. Chem. Soc. 2005, 127, 13136.

10. (a) Shimizu, K. D.; Rebek, Jr., J. Proc. Natl. Acad. Sci. U. S. A. 1995, 92, 12403. (b) Mogck, O.; Paulus, E. F.; Böhmer, V.; Thondorf, I.; Vogt, W. Chem. Commun. 1996, 2533. (c) Rebek, Jr., J. Chem. Commun. 2000, 637. (d) Rudzevich, Y.; Bogdan, A.; Vysotsky, M. O.; Böhmer, V. in Calixarenens in the Nanoworld; Vicens, J.; Harrowfield, J.; Baklouti, L. Eds.; Springer: Dordrecht, 2007; pp 21-46.

11. Liang, C.; Mislow, K. J. Math. Chem. 1994, 16, 27.

12. (a) Habiro, K. Math. Proc. Comb. Phil. Soc. 2007, 142, 459. (b) Bardakov, V. G.; Mikhailov, R. V. Siberian Math. J. 2007, 48, 387.

13. Corey, E. J.; Cheng, X.-M., The Logic of Chemical Synthesis, J. Wiley and Sons, New York, 1989.

14. (a) Cao, J.; Fyfe, M. C. T.; Stoddart, F. F.; Cousins, G. R. L.; Glink, P. T. J. Org. Chem. 2000, 65, 1937. (b) Hogg, L.; Leigh, D. A.; Lusby, P. J.; Morelli, A.; Parsons, S.; Wong, J. K. Y. Angew. Chem. Int. Ed. 2004, 43, 1218. (c) Dichtel, W. R.; Miljanić, O. Š.; Spruell, J. M.; Heath, J. R.; Stoddart, J. F. J. Am. Chem. Soc. 2006, 128, 10388. (d) Keaveney, C. M.; Leigh, D. A. Angew. Chem. Int. Ed. 2004, 43, 1222.

15. (a) Glink, P. T.; Oliva, A. I.; Stoddart, J. F.; White, A. J. P.; Williams, D. J.; Angew. Chem. Int. Ed. 2001, 40, 1870. (b) Klivansky, L. M.; Koshkakaryan, G.; Cap, D.; Liu, Y. Angew. Chem. Int. Ed. 2009, 48, 4185.

16. Ashton, P. R.; Belohradsky, M.; Philp, D.; Stoddart, J. F. J. Chem. Soc., Chem. Commun. 1993, 1269. (b) Ashton, P. R.; Ballardini, R.; Balzani, V.; Belohradsky, M.; Gandolfi, M. T.; Philp. D.; Prodi, L.; Raymo, F. M.; Reddington, M. V.; Spencer, N.; Stoddart, J. F.; Venturi, M.; Williams, D. J. J. Am. Chem. Soc. 1996, 118, 4931. (c) Asakawa, M.; Ashton, P. R.; Ballardini, R.; Balzani, V.; Belohradsky, M.; Gandolfi, M. T.; Kocian, O.; Prodi, L.; Raymo, F. M.; Stoddart, J. M.; Venturi, M. J. Am. Chem. Soc. 1997, 119, 302.

17. Brunn, H. S.-Bayern Math.-Phys. Kl., Bayern Akad. Wiss. 1892, 22, 77.

18. (a) Park, K.-M.; Kim, S.-Y.; Heo, J.; Whang, D.; Sakamoto, S.; Yamaguchi, K.; Kim, K. J. 
Am. Chem. Soc. 2002, 124, 2140. (b) Ko, Y. H.; Kim, K.; Kang, J.-K.; Chun, H.; Lee, J. W.; Sakamoto, S.; Yamaguchi, K.; Fettinger, J. C. J. Am. Chem. Soc. 2004, 126, 1932.

19. (a) Vysotsky, M. O.; Thondorf, I.; Böhmer, V. Chem. Commun. 2001, 1890. (b) Vysotsky, M. O.; Thondorf, I.; Böhmer, V. Angew. Chem. Int. Ed. 2000, 39, 1264.

20. Flapan, E. When topology meets chemistry; Cambridge University Press: Cambridge, 2000, reprinted 2007; p. 2.

21. Ashton, P. R.; Baxter, I.; Fyfe, M. C. T.; Raymo, F. M.; Spencer, N.; Stoddart, J. F.; White, A. J. P.; Williams, D. J. J. Am. Chem. Soc. 1998, 120, 2297.

22. Cram, D. J. and Cram, J. M. Container Molecules and Their Guests, in Monographs in Supramolecular Chemistry; Stoddart, J. F. Ed. The Royal Society of Chemistry, Cambridge, 1997.

23. (a) Hill, D. J.; Mio, M. J.; Prince, R. B.; Hughes, T. S.; Moore, J. S. Chem. Rev. 2001, 101, 3893. (b) Berni, E.; Kauffmann, B.; Bao, C. Y.; Lefenvre, J.; Bassani, D. M.; Huc, I. Chem. Eur. J. 2007, 13, 8463.

24. Such operation not always leads to the constant growth of the link, for example, the endless repetition of the composition of one ring and one [2]-catenane gives only [2]-catenane; the same is true for any link: ring \# link = link.

25. A pseudo-[2] rotaxane is made in this way.

26. Frisch, H. L.; Wasserman, E. J. Am. Chem. Soc. 1961, 83, 3789.

27. Another strike difference is the energy barrier of these two bonds. While the "mechanical bond" is build due to directed repulsion forces predominantly and can assume quite low values (see also ref. 12), the free energy of the topological bond is always the energy of the weakest covalent bond which is to brake to dissociate the units connected "topologically" with each other. Most probably, there can be a difference in some cases at least in one order of the magnitude.

28. One mechanical bond corresponds to two crossings in the reduced diagrams of the examples discussed.

29. Radha Kishan, M.; Parham, A.; Schelhase, F.; Yoneva, A.; Silva, G.; Chen, X.; Okamoto, Y.; Vögtle, F. Angew. Chem. 2006, 118, 7454.

30. Lagona, J.; Mukhopadhyay, P.; Chakrabarti, S.; Isaacs, I. Angew. Chem. Int. Ed. 2005, 44, 4844.

31. (a) Kim, K. Chem. Soc. Rev. 2002, 31, 96. (b) Tuncel, D.; Steinke, J. H. G. Chem. Commun. 2002, 496. (c) Jeon, Y.-M.; Whang, d.; Kim, J.; Kim, K. Chem. Lett. 1996, 503. (d) Isobe, H.; Sato, S.; Nakamura, E. Org. Lett. 2002, 4, 1287.

32. Fyfe, M. C. T.; Glink, P. T.; Menzer, S.; Stoddart, J. F.; White, A. J. P.; Williams, D. J. Angew. Chem. Int. Ed. 1997, 36, 2068.

33. The important additional condition should be kept: the disconnection of only one dumbbell leads necessary to the disconnection of all further dumbbells from the ring.

34. It would not be different methodologically if any of the supramolecular bonds (hydrogen bond, $\pi-\pi$, etc.) would replace a covalent one. For the sake of clearness, I avoid deliberately 
here the combinations with several connections between only one ring of one sublink with several rings of the second sublink.

35. One has to note, this system is not quite convenient for the typing and in the cases of links with one unit, is based partly on the position within the well known Tables: Appendix C: Table of knots and links in Rolfen, D. Knots and Links; Publish or Perish: Berkeley; 1976; second printing with corrections: Publish or Perish: Houston; 1990.

36. See, for instrance: Fang, L.; Hmadeh, M.; Wu, J.; Olson, M. A.; Spruell, J. M.; Trabolsi, A.; Yang, Y.-W.; Elhabiri, M.; Albrecht-Gary, A.-M.; Stoddart, J. F. J. Am. Chem. Soc. 2009, $131,7126$.

\section{Author's biography}

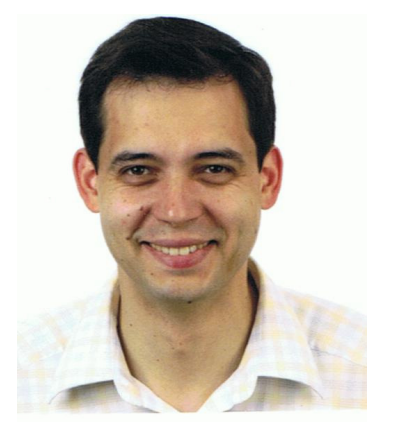

Myroslav O. Vysotsky was born 1971 in Kiev (Ukraine). He obtained his Diploma in Chemical Engineering of Organic Compounds in 1994 from National Technical University "Kiev Polytechnical Institute" and Candidate of Sciences in Organic Chemistry (PhD's equivalent) in 1998 from Institute of Organic Chemistry of National Academy of Sciences of the Ukraine (Kiev, Ukraine) for his work conducted on O-phosphorylated Calixarenes in the group of Vitaly I. Kalchenko. He worked one year as The Royal Society / NATO \& FCO Chevening postdoctoral fellow with Christopher A. Hunter (Sheffield, UK) before he joined the group of Volker Böhmer (Mainz, Germany) in May 1999 as a post-doctoral research associate. 2001 - 2008 he worked simultaneously as practicums and seminars assistant in Organic, Physical and Supramolecular Chemistry at the Department of Chemistry, Pharmacy and Geosciences of Johannes Gutenberg - University (Mainz, Germany). He was awarded the Forschungsstipendium of the German Research Foundation (Deutsche Forschungsgemeinschaft, DFG) and later (2006 2008) became a project leader of DFG ("eigene Stelle") at the same Institution. Since July 2008 he is unemployed. His research interests include mechanically bound systems, self-assembled molecular capsules and physical chemistry of non-covalent interactions. He is a co-author of 60 publications. 